\title{
LEPROSY IN NIGERIA
}

The following is the report on a short tour in Nigeria between the 2Ist of August and the I4th of September, I939. Its objects were to visit certain of the leprosy institutions, especially those in which agents of B.E.L.R.A.-Toc $\mathrm{H}$ are working; to study progress made in leprosy relief and control since 1936, when a previous visit to Nigeria was made; and to attend a leprosy conference called by the Director of Medical Services and held at Enugu from the 28th to the 3oth of August. Readers are referred to Leprosy Review, October 1936, which records a previous similar tour.

\section{LEPROSY INSTITUTIONS}

Eight leprosy institutions were visited : Yada Kunyu (Kano Province), Zaria, Oji River, Uzuakoli, Itu, Ossiomo, Ilesha and Ogbomosho. A few notes are recorded on each of these.

Yada Kunyu Leper Settlement is situated 9 miles to the East of Kano City. It has taken the place of the former settlement at Somaila which was abandoned on account of its inaccessibility and the difficulty of obtaining water. The present settlement was begun 18 months ago by the Sudan Interior Mission, which supplied the staff consisting of the Medical Superintendent, two sisters and an industrial supervisor. The cement-block dispensary, the water supply, the road from Kano and part of the drugs have been provided by Government; while the other buildings, the equipment and part of the drugs have been contributed by the S.I.M. and the American Mission to Lepers. The Native Administration has supplied $£ 84$ I towards patients' subsistence and drugs.

There were 293 patients at the end of March, 1939. I examined the 27 patients admitted in the last three months and found that $60 \%$ were neural cases with tuberculoid lesions, and $22 \%$ were lepromatous; so. that the proportion of types is similar to that in most other parts of Africa visited.

I was shown a number of lepers, both adults and children, suffering from eye symptoms. In most of these there were signs of either present active trachoma or of scarring and trichiasis, the effects of former active trachoma.

Much progress has been made in this well-staffed settlement, and it is hoped to raise the number of patients to five hundred. Out-patient and educative work is also being undertaken with a view to leprosy control.

The settlement at Somaila was begun along the right lines, and the treatment of patients is now being continued on the same lines and under much more favourable circumstances on the new site. Stress is laid upon occupational therapy, both agricultural and industrial occupation being arranged for. If the number rises to 500, more land will be required. Particular care is being taken 
of the children, and it is hoped soon to establish a creche. The lepers themselves are being taught to help in nursing and treatment.

The Native Administration is particularly fortunate in having the Mission to care for the lepers of the province. The same Mission has also leper settlements on similar lines in the Katsina and Sokoto Provinces and is contemplating still further extensions.

Zaria Leper Settlement. This institution was begun by the Government some years ago and was handed over to the care of the Church Missionary Society in October, 1937. It lies some 9 miles to the south of Zaria, adjacent to the Zaria-Kaduna road. It is about $4 \frac{1}{2}$ miles from the C.M.S. Hospital at Wusasa, from which it is visited by the hospital doctor. The settlement has resident staff of a Toc $\mathrm{H}$ lay worker and a lady sent out by B.E.L.R.A. and, during the latter's absence on leave, a nursing sister from the hospital. The Nigerian Branch of B.E.L.R.A. and the Native Administration have supplied most of the cost of the treatment block, which is a permanent structure. The patients are lodged in huts arranged in rows.

The Native Administration gives an annual contribution of $£ 350$ for patients' subsistence, which maintains I07 patients. There are also $3 \mathrm{I}$ disabled pensioners in whom the disease has disappeared, who are maintained for the present by special donations from the Native Administration and Europeans in Zaria. The maintenance allowances are handed over to the patients in cash, each of them buying his or her own supplies.

I had an opportunity of examining all the inmates including the pensioners, and classified them roughly into 27 severe lepromatous $\left(\mathrm{L}_{2}\right.$ and $\left.\mathrm{L}_{3}\right) ; 7$ slight lepromatous $\left(\mathrm{L}_{1}\right) ; 47$ neural cases with tuberculoid lesions, 25 of whom showed no deformity or disablement; 36 in whom active signs had disappeared, and 26 in whom signs of present or past leprosy were not discovered.

There was a tendency on the part of some of the patients to act as if they suffered from anaesthetic lesions which, on careful examination were not found to exist. This wishful acting is perhaps to a certain extent a sign of the popularity of the settlement and the aversion of patients to being discharged.

There were 62 patients in whom active lesions could not be discovered, from which may be deducted the $3 \mathrm{I}$ pensioners, leaving 3 the most of whom, if further examination fails to show active signs, might be discharged. This would make room for new admissions, and I understand that many patients are seeking admission.

The Zaria institution was begun as an asylum or refuge, and naturally a large proportion of the inmates were hopelessly crippled 
cases who had sought refuge in the last stages of the disease. It is always difficult to transform such an institution into a hopeful active settlement to which patients come with the object of recovering and being restored to their normal status in the community. It is much easier to begin a fresh settlement like that at Kano with the latter object in view from the outset.

The lot of the 3I pensioners and such ex-leper patients as, on account of their deformities, cannot be taken back into their homes is a sad one, and humanity demands that they should be cared for; but as long as they are kept in the Zaria settlement they are bound to influence adversely the hopefulness of the institution and prejudice the chance of recovery of otherwise hopeful cases. A suggestion is offered later of a method of arranging for such cases.

As at Yada Kunyu settlement, I found a large amount of eye trouble. Examination of 23 adults showed 3 active cases of trachoma, 6 others with old trachoma scars but no trichiasis, and 7 with trichiasis. In no case did I find the eye condition to be due to leprosy. In I4 children I found 2 doubtful and 6 definite cases of active trachoma and I with scars of former trachoma.

The brightest outlook at the Zaria settlement is the organisation of the social side. There are about 40 acres of arable land which have been developed with the aid of the Agricultural Department. But more land is needed if the settlement is to expand and supply tood for the patients.

The European resident staff is lodged in mud houses which have been condemned on account of their proximity to a swamp. A suitable site for new houses is available and their construction should be proceeded with without delay. I think it would be wise to make them of a more permanent type and this could be done without undue expense.

With regard to the present distribution of maintenance allowances to the patients, I consider it is a mistake to give these in the form of cash for the following reasons. There is no assurance that the patients use these for their own nourishment; buying at retail prices is always more expensive than buying wholesale; many foodstuffs may be bought more favourably in the cheap season and stored and distributed later.

Many of the neural cases might become arrested quickly through the use of intradermal injections, and by radical operations on their feet for removal of bone. There might thus be a much quicker turn-over of patients and the popularity of the institution would be still further increased.

The B.E.L.R.A. has undertaken to supply a whole-time doctor for leprosy work and he is expected to arrive about the end of the year. 
The Native Administration is extremely fortunate in having this leper work undertaken by such an efficient and devoted staff, with so little expense to themselves; but the institution as it stands at present is not an economical proposition. There are hundreds of lepers in Zaria province; they are seeking admission to the settlement voluntarily; the staff is able to deal with far more cases but cannot admit them for want of subsistence money and for want of sufficient farm land, and the health of the staff is endangered for want of suitable quarters. The Zaria province is a poor one, but I believe that every effort will be made by the Native Administration to support the settlement adequately when the above facts are understood.

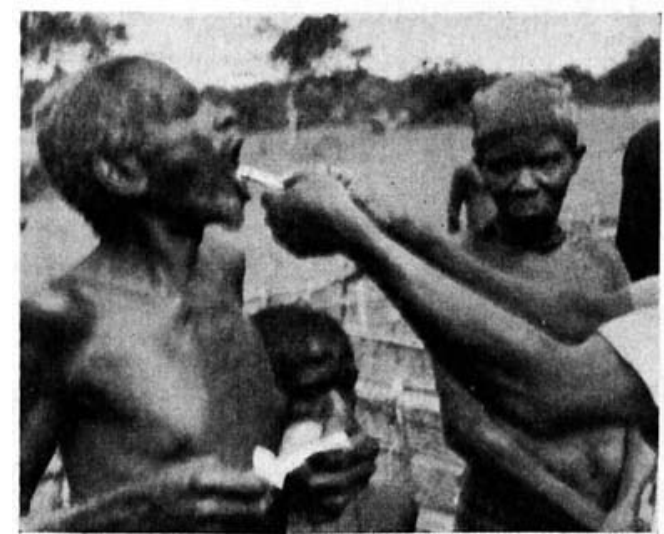

FIG. 10.

OjI River Leper Settlement : administering an anthelmintic with a hypodermic syringe.

Oji River Settlement. This institution aims at relieving and controlling leprosy in the Onitsha Province, at the centre of which it is situated; it is distant by 27 miles from Enugu and by 40 from Onitsha town. In addition to 250 in-patients, it supplies out-patient treatment to some 3,000 lepers at Agulu in the Awka Division, Awwa in the Udi Division, and at the settlement itself. It is hoped soon to open other clinics in the Nsuka and Onitsha Divisions. At present the staff has been almost overpowered with the voluntary attendance of out-patients, but it is hoped as soon as possible to organise from these clinics as centres, educational and preventive work in the villages, and at the same time gradually complete a survey of leprosy in the province. These clinics are conducted by the doctor and the lay workers, with the assistance of the African staff, consisting chiefly of suitable patients who have been trained for the work. 
The central buildings include a hospital and treatment centre. The patients live in huts of the native style.

The staff consists of a doctor, two or three B.E.L.R.A.-Toc H lay workers and a nursing sister. The settlement is conducted by the Church Missionary Society. The doctor is supplied by the Halley Stewart Fund through B.E.L.R.A. The Leprosy Association provides the rest of the European staff and are supplying a second doctor towards the end of the year. The staff are housed in excellent permanent houses.

As from April, 1938, the Native Administration of the province are supplying for three years the sums of $£^{\mathrm{I}}, 500, £ \mathrm{I}, 700, £ \mathrm{I}, 700$, for general maintenance, including $£$ I30 a year for the maintenance of patients who are unable to support themselves.

The rule is adhered to as far as possible that each patient has to pay each year $£^{2}$ for the services of the settlement, including the hire of farm land. Able-bodied patients earn ninepence to half a crown per week by doing four or more hours work a day on the settlement farm, or in other work of the community. Suitable work at similar wages is provided for those who are less able. Weak patients are admitted to hospital and when necessary are exempted from the annual fee; they are also put on special diet during the time they are in hospital.

Land, averaging $\frac{3}{4}$-acre each, is given to patients according to their ability to cultivate it usefully. Thus patients maintain themselves on their wages and on the produce of their own farms, the disabled being assisted according to the degree or nature of their disablement. The communal farm is used to try and instruct (so far with poor results) the patients in improved methods of farming; in this the Agricultural Department has given much help.

Many more patients could be admitted if funds were available, and it is expected later to raise the number to 500. In the mean. time not only are large numbers of patients being treated, but valuable public health education is going on, and the people and their chiefs are becoming conscious of the nature and seriousness of leprosy, and that through simple means within their control it can be prevented.

The work of the settlement is well organised, each member of the European staff being responsible for one or more departments. As farming and industries develop approximation to self-support may be reached. Negotiations are under way for an additional Ioo acres of land adjacent to the settlement, and on the south side of the Enugu-Onitsha road. Acquiring this land will increase the scope of the farming, and will also make it possible to control the breeding places of mosquitoes and make the settlement more healthy as regards malaria for both staff and patients. This, I 
consider, an important point, and it is to be hoped that the land will be acquired without delay. The absence of towns and villages within a radius of five miles has made the acquisition of land easier than in other places.

The Oji River Settlement is planned upon different lines from other leper institutions. The settlement is not an end in itself, but a centre for treatment of special cases and for training of staff, with the ultimate object of getting at the root of the problem and stamping out leprosy from the province with the help of the people themselves. These methods, which have for some time been employed in India, are worthy of study by others engaged in anti-leprosy work.

Uzuakoli Leper Scttlement. This Native Administration Institution is situated in the Owerri Province, some 75 miles south of Enugu.

The Medical Superintendent is a missionary of the Methodist Mission and he is assisted by two Toc $\mathrm{H}$ lay workers supplied by B.E.L.R.A. and four non-leper Africans. The rest of the work is done by patients. There are eleven hundred patients housed in neat rows of sanitary huts, arranged in villages within the Settlement.

The hospital, treatment centre and other administrative build.. ings and the European Staff quarters are of a permanent type, and have been erected chiefly with the labour of patients.

The treatment arrangements are excellent, including occupation therapy in all its forms and communal physical exercises. Agriculture and industries make the settlement partly self-supporting. The annual expenditure on running expenses, including the doctor and the rest of the staff except the two Lay Workers, is only $£ 3,000$. Of this sum $£ I, 500$ is paid by the Native Administration, and $£ 800$ by Government. The settlement might be made even more self-supporting but for the fact that more than $50 \%$ of the patients are of the severe lepromatous type, many of whom are incapable of doing more than very light work. This, the infectious type of leprosy, is the chief danger to the community and it is felt that as many of them as possible should be segregated in the settlement.

Excellent teaching and training are provided for the patients, many of whom are able to help in administrating treatment and in carrying out leprosy control methods in the villages.

The Settlement has made considerable progress since my last visit in 1936. One of the most important developments is along the lines of survey, village prevention, and out-patient clinics. Many patients continue to seek admission to the settlement, but the numbers have had to be limited. Out-patient treatment in villages 
is in great demand and is gradually being introduced, but only in places where the whole-hearted co-operation of the people and their chiefs has been obtained. It is felt that treatment alone will never control leprosy if those under treatment are at the same time infecting others in their own homes.

In this direction a very interesting experiment is being made in educating the community and introducing self-help in the villages. A village is chosen where the co-operation of the chief and people is assured. A building for a clinic is erected by the villagers. A house to house survey is made, all cases of leprosy being noted down. The village has to supply land for the erection of a hamlet where all these lepers can be segregated and can cultivate their crops. This hamlet is erected by the lepers themselves under the direction of the settlement staff, a suitable trained patient from the settlement being left in charge of the work. At the same time a weekly clinic is started and a patient is left as dresser to attend to ulcers and to see that patients remain properly isolated. Default in this respect is penalised by refusal of treatment, which is regarded as a serious punishment, so highly is treatment prized. Already seven such out-clinics have been begun. I had an opportunity of visiting one of them and was greatly taken with the enthusiastic spirit of the people, both patients and others. I found the new leper hamlet a well laid out spacious hamlet, with roomy huts, a simple but effective model in sanitary village building.

This plan of controlling leprosy is still in the experimental stage, but it seems to get down to the very roots of leprosy control. It has been made possible by the very modest grant of $£$ I20 from Government, which is more than used up in transport, drugs and the salaries of the African staff. Under the doctor the work is in the charge of one of the Toc $\mathrm{H}$ lay workers. I would emphasise the importance of this experiment, not only for its leprosy control value, but also as an effective general public health measure. I consider that it should receive very active support from the Native Administration and Government.

The Uzuakoli Settlement is thus much more than a wellorganised centre for segregation and treatment of lepers. It is rather the hub of a wheel which is gradually radiating into the village life of the people. It is a centre of training of leprosy patients who are found to be the most enthusiastic and efficient apostles of anti-leprosy methods. Its sanitary village planning is gradually " taking on" with the people. What astonishes one most is the modest cost at which all this is managed, though doubtless with more resources it could be more rapidly expanded and more effectively done. 
Itu Leper Settlement. This institution was founded in 1928 by Dr Macdonald, of the Church of Scotland Mission. It was the first in the country to be begun in the form of an agricultural settlement, and later institutions have been modelled on similar lines.

The institution is fortunate in having, abundant land, the extent of which has now risen to three square miles; this, along with the industries, makes it possible to develop self-support to a very great extent. The products of agriculture and industries last year were valued at $£$ I, I25.

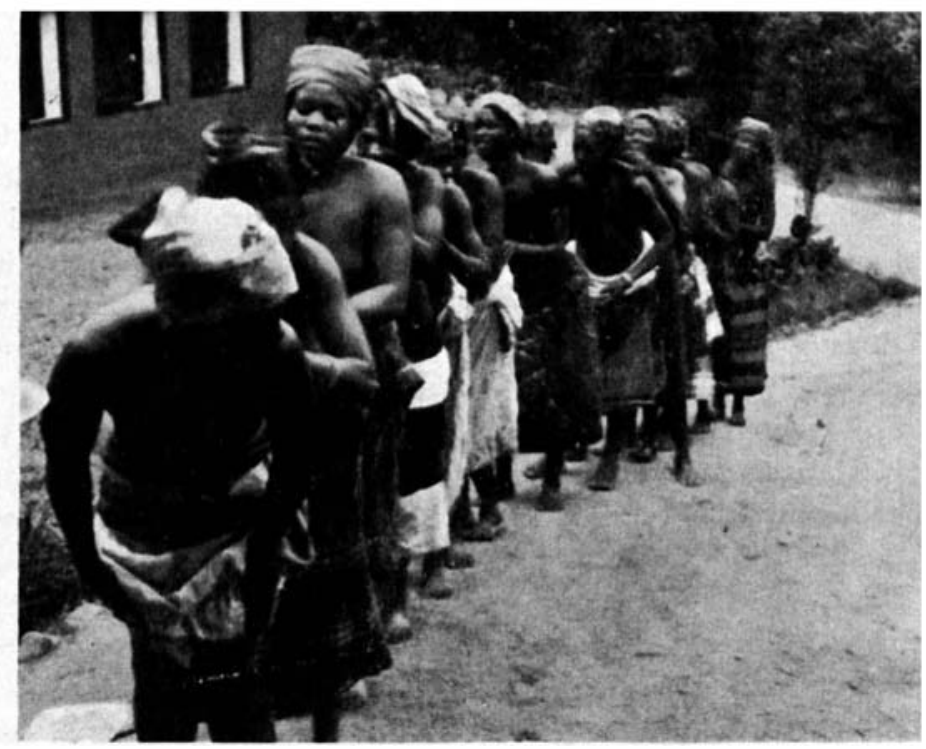

Fig. 11. Oil inunction at ltu Leper Settlement.

The European Staff consists of the Medical Superintendent and an Industrial Worker, for whose support an annual grant of $£^{\mathrm{I}, 000}$ is given by Government, and two Toc $\mathrm{H}$ workers supplied by B.E.L.R.A. The Medical Superintendent's wife is a trained nurse and has trained the African nurses. A further grant of $£$ I,, 00 is given by Government and a capitation grant of $£ 700$ by the Native Administration. The African staff consists of two non-leper dispensers and 5 nurses for the creche; also a laboratory assistant, headmaster and engineer, who formerly suffered from leprosy. Otherwise all the work is done by the patients themselves.

There are at present in the colony some 2,200 patients. Of these some 400 are unable to do more than occasional or light work. They include some 80 hospital patients and the school children; the latter are employed for two hours a day on the work of 
the settlement. Able-bodied patients do two days' work a week in return for service received. They also are given work for which they are paid on a contract basis and are employed for two out of every three weeks for about 35 hours a week. The older children are employed, some 52 at a time, as temperature-takers, for which they are paid at ninepence a week. The large majority of patients have to bring $£ 3$ when admitted to the settlement to pay for their food during the first three years, after which they have to collect $f$ I a year from relatives if longer treatment is required. This, unfortunately, excludes the poorer type of patient, but it has been found the only method practicable under present financial conditions.

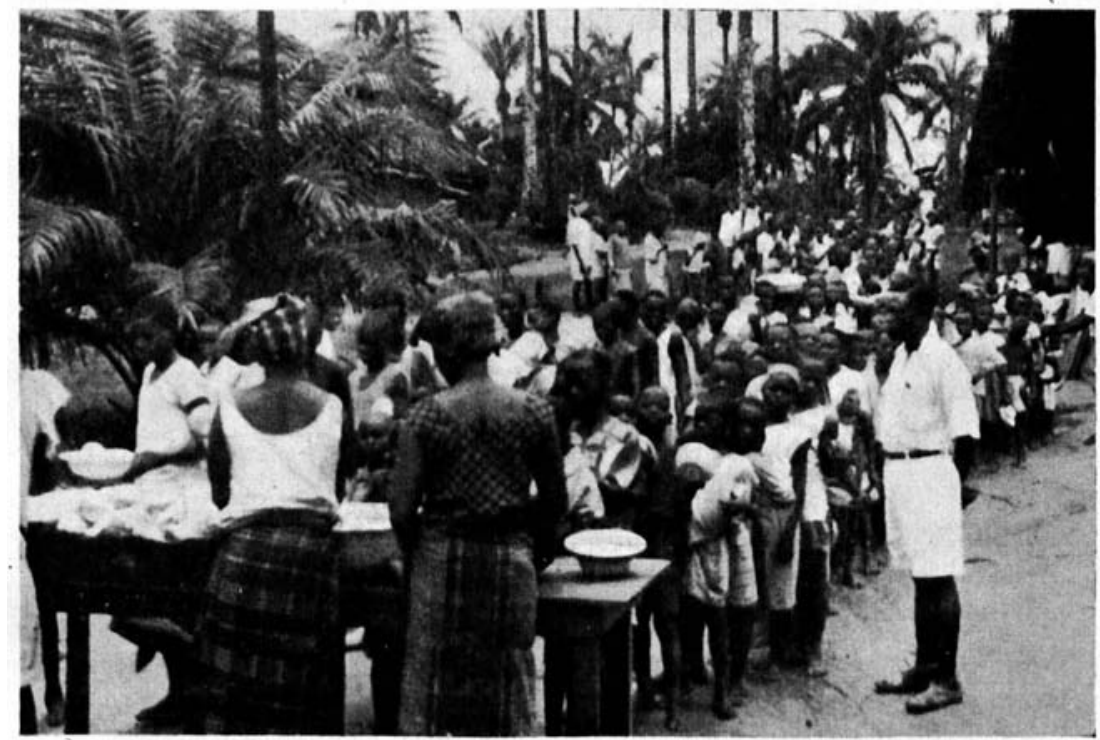

liki. 12. Itu Setrlement : the children's daily ration.

The principal crops raised in the Settlement consist of yam, coco-yam, casava, rice and palm-oil, with subsidiary crops of hydnocarpus, ground nuts, pawpaw, soya and various vegetables. Industries consist of palm-oil, timber, soap manufacture, etc.

There are a large school for the children and two adult schools, an excellent brass band, and such activities as Scouts, Cubs, Guides and Brownies. The church holds I,800, and is usually crowded at services.

The discipline of the settlement is maintained by a leper court and leper police. The whole place is excellently organised as regards treatment, finance, and the social, mental, physical and spiritual life of the people. It must have a profound effect on the 
life of the country through returned patients who have spent several years in the settlement.

Unfortunately, the greater part of this influence is likely to be exerted in other parts of Nigeria rather than close at hand. Only about 350 to 400 patients come from among the Ehik-speaking people of Calabar, the great majority being from other provinces. The Efik people are apparently a servile race, having formerly been slaves and sufferers from the slave trade. In consequence it is harder to win their co-operation in a campaign against leprosy than among Ibo tribes in the Owerri and other provinces; and yet a survey of 4,626 people showed an average incidence of at least 7.6 per cent., which, if it holds throughout, would mean a total number of some 76,000 lepers in Calabar Province. . How this huge incidence is to be dealt with on a provincial basis is a matter requiring careful consideration.

Ossiono Leper Settlement. This institution is situated in the Benin Province, and receives patients from Benin and Warri Provinces. It was begun originally as an asylum of the old type, the most of the inmates being disabled and either unwilling or unable to work. Five years ago, Dr. Lengauer was appointed as Medical Superintendent and set about transforming the institution into an agricultural settlement on the lines of Itu and other modern leper settlements. In this work she has been badly handicapped by the tradition of the original patients. It is always easier to form an agricultural settlement from the beginning than to transform an already existing asylum. The site is a most unsuitable one. The land is inadequate and more is difficult to obtain. The soil is of a poor quality. Apart from a limited amount of rain water collected from the roofs of the permanent buildings, the water has to be carried from a stream more than a mile distant.

In spite of all these difficulties much progress has been made in the last three years since my former visit (Leprosy Review, I936, p. 180). There are now 325 in-patients and 75 attend regularly as out-patients. Of the 325 in the settlement, II2 are lepromatous (34 per cent.). Although the number of patients has increased, the Native Administration grants are still the same, and 55 of the patients have been admitted on a self-supporting basis. Large numbers of patients, especially of the lepromatous type, present themselves for admission, but during the last six months it has been necessary to turn away Ioo cases for lack of accommodation and funds. These applications for admission have increased considerably since II patients were discharged as disease-arrested I8 months ago. 
The income of the settlement is derived as follows:--.-

Native Administrations (Benin and Warri Provinces) ... $\quad$ 1,590

Government, through Nigerian Branch of B.E.L.R.A. 50

$\begin{array}{lllllll}\text { From paying patients } & \ldots & \ldots & \ldots & \ldots & \ldots & \text { I00 }\end{array}$

$\begin{array}{llllllll}\text { From farms } & \ldots & \ldots & \ldots & \ldots & \ldots & \ldots & 20\end{array}$

Of these sums $£ 550$ supports the Medical Superintendent and her two European assistants (a nursing sister and a welfare worker); $£ 600$ is spent on the subsistence of patients; $£$ I20 on drugs; $£ 80$ on bedding and clothing; $£ 40$ on repairs to buildings; $£ 60$ on the clerk and messenger. The patients are given one shilling a week, except 42 who get sixpence and a few who are entirely self-supporting. In the creche there are 18 babies of lepers. Of the patients, 224 are men, 60 women and 43 children.

An " Ossiomo Aid Society " in Belgium renders some financial help from which school teachers, home passages and various services are met.

From what Dr. Lengauer tells me I gather that leprosy is very prevalent in the Benin and Warri Provinces. As an example, in three villages with a population of about 2,800 , some 60 lepers presented themselves voluntarily on one visit, although there was at the time pouring rain; presumably there were many more.

Lepers driven out on becoming disabled or disfigured sometimes form themselves into separate village communities. Of these there are known to be seven, with a total population of about 192 cases. The condition of these people is pitiable as nothing is done for them. Many wander about and the women are often found trading in the markets.

The people themselves say that formerly they drove out all known lepers and that then leprosy was less; now they are allowed to remain in the villages as long as they are able to work, and leprosy is accordingly increasing. Some signs of co-operation are, however; found; for instance, one chief has sent an intelligent youth to be trained at his expense at the settlement, with a view to controlling leprosy in his village.

There is no doubt that in these provinces leprosy is a major problem, and that, if anything effective is to be done to control it, the devoted work at Ossiomo will need to receive considerably more support.

Ogbomosho Leper Settlement. This is the only settlement in the Yoruba country. It is situated a few miles outside this city of some 80,000 inhabitants, and is run by the American Baptist Mission, who receive a grant of $£ 330$ a year from the Native Administration. 
There are at pre'sent 75 in-patients living on and farming the 180 acres of settlement land. There are also I50 out-patients who attend for treatment and live in small farms which they cultivate in the neighbourhood of the settlement. With a few exceptions these patients come from the Oyo Province, in which the settlement is situated.

With the help of the Agricultural Department, crop rotation and the use of macuna (green manure) is being attempted. It is found that the patients, those both inside and outside the settlement, with the exception of the few who are unable to work, are able to support themselves by cultivation. The patients, on the whole, appear to be well nourished.

Until six months ago patients were refused admission unless able to work. At present about 50 per cent. are lepromatous, and 50 per cent. neural cases, chiefly with tuberculoid lesions. I was surprised at the large proportion of major tuberculoids, some of them in a state of active reaction.

Many patients seeking admission are turned away, as the Administration has set a limit to the number in the settlement. Among the complicating diseases of admitted patients trachoma and pyorrhoea are not uncommon.

It is commonly reported that leprosy is much less frequent among the Yorubas than elsewhere in Nigeria. I understand, however, from Dr. Glenn Walker, the Medical Superintendent of the settlement, that there is probably far more than is generally supposed. He states that a chief who is asked if he has any lepers in his town, denies the fact according to the custom of the tribe, it being considered wrong for a Yoruba chief to disclose any defects among his people. Where chiefs have denied cases, numbers of lepers have been found in the neighbourhood of his house.

I understand that, though funds are available, the authorities are opposed to increasing the grants or the number of patients in the settlement until a survey has been rnade to determine the number of lepers in the province. One of the resolutions at the Enugu Conference was to the effect that " detailed surveys employing special staff are undesirable if not associated with the offer of treatment." This would apply more especially to the Yorubas, who generally have a town and a farm residence, and can therefore easily withdraw from the one to the other to escape detection if their suspicions as to the objects of a survey were once wakened. The only feasible method of forming an idea of the incidence of leprosy is by forming clinics at different suitable centres throughout the province, and attracting patients by giving them treatment. It would probably be necessary at the same time to attach a certain amount of arable land to each clinic, as the patient who attends is 
liable to become publicly known as a leper, and it is the custom to drive the publicly known leper from his home. Ir. Walker contemplates gradually founding such clinics, and I consider that he should be given facilities, financial and otherwise, for taking this step. It appears to be the only immediate means of advancing anti-leprosy work and ascertaining the seriousness of leprosy in the Oyo Province. To help in the conduct of clinics, Dr. Walker has begun training some of the more intelligent patients at the settlement.

I disagree with the suggestion that the leprosy problem should be shelved until the improvement of general hygiene and nutrition has caused it to disappear; the experience of other provinces mentioned in this report exposes the fallacy of this point of view.

With a view to developing clinics, Toc $\mathrm{H}$ workers were supplied by B.E.L.R.A. to the Ogbomosho Settlement and have done good work there; and I would recommend that if and when the Administration encourage a forward policy and ask for the return of Toc $\mathrm{H}$ workers, B.E.L.R.A. should consider such a request favourably. 